\section{The permanence of ECS effects in a one-trial discriminated avoidance paradigm*}

\author{
ABRAHAM A. SPEVACK $\dagger$ \\ Queen's University, Kingston, Ont., Canada
}

Postlearning tests were conducted on the 1st or 30th and 31st days after a single discriminated avoidance trial. Although significant effects on choice latency produced by ECS were not observed on the day after training, statistically reliable ECS-produced reductions in choice latency were apparent on the 30 th and 31 st days after learning. No statistically significant effects of ECS on discrimination or defecation rates were observed on any postleaming test.

In marked contrast to data produced by passive avoidance experiments (e.g., Spevack, Rabedeau, \& Spevack, 1967), recent research has indicated that the effect of ECS on both discrimination and latency measures of a one-trial discriminated avoidance task is constant for a variety of learning-ECS intervals between $100 \mathrm{sec}$ and $20 \mathrm{~h}$ long (Suboski, Spevack, Litner, \& Beaumaster, $1969 \mathrm{~b})$. The authors concluded on the basis of these and subsequent data (Suboski, Black, Litner, Grenner, \& Spevack, 1969a) that ECS effectively interferes with memory consolidation only if the convulsion follows learning within $30 \mathrm{sec}$. The constant ECS effects they observed for longer learning-ECS intervals they attributed to ECS effects other than those on memory. One such frequently reported result of ECS (e.g., Brengelmann, 1959) is a temporary deficit in the performance of well-learned tasks produced by a series of postlearning convulsions. A notable characteristic of this ECS-produced performance decrement is that it slowly dissipates with time, indicating that it is not due to a disruption of memory storage processes. Such an ECS effect may well account for Suboski et al's atypical results. To test this possibility, the present study, unlike previous attempts to assess the permanence of ECS effects (e.g. Greenough, Schwitzgebel, \& Fulcher, 1968; King \& Glasser, 1970; Pagano, Bush, Martin, \& Hurt, 1969, Riddell, 1969), used a one-trial discriminated avoidance paradigm. Recovery of

* This study was adapted in part from a dissertation submitted by the author to the School of Graduate Studies of Queen's University in partial fulfillment of the requirements for the $P h D$ degree. This research was supported by Grant APA-244 from the National Research Council of Canada and by Grant 161 from the Ontario Mental Health Foundation. I thank Dr. $M$ D. Suboski for guidance and support and Mr. Manuel Black for assistance.

+Presently at Department of Psychology. Virginia Polytechnic Institute and State University, Blacksburg. Va. 24061. discrimination and latency levels after a 30-day postconvulsion interval in this experiment would indicate that performance, not memory, is affected by ECS in one-trial discriminated avoidance experiments using learning-ECS intervals longer than $30 \mathrm{sec}$.

Chorover \& Schiller (1966) have attributed the effects of ECS at learning-ECS intervals longer than $30 \mathrm{sec}$ to the releasing by convulsions of the immobility produced as a behavioral adjunct of a conditioned emotional response. Furthermore, they suggested that the reduction of freezing behavior was a direct result of altered motor behavior of Ss when reintroduced into the learning situation after training and convulsion rather than an indirect result of emotionality reduced by ECS. As evidence, Chorover and Schiller indicated that ECS had no effect on the increased defecation rates produced by footshock; however, they did not provide data. The present experiment was designed to do so by the use of bolus counts.

\section{SUBJECTS}

The Ss, as in Suboski et al's (1969b) experiments, were male Long-Evans rats obtained from the Canadian Breeding Laboratories at 85-100 days of age. The rats were individually housed and allowed free access to Purina Lab Chow and water in their home cages. Ss were handled for $5 \mathrm{~min}$ a day for each of the 2 days following delivery and before they were used in the experiments.

\section{APPARATUS}

The same apparatus as described by Suboski et al (1969b) was used in this experiment. An unpainted open field in the shape of a right-angled triangle, with two of the 18-in.-high plywood sides $22 \mathrm{in.}$ long and the third $20 \mathrm{in}$. long, had small covered chambers cutting off the two acute angles. Each of the small chambers had inside dimensions of 6 in. deep, 5 in. wide, and $6 \mathrm{in}$. high. One of the chambers was painted white inside and outside and had a round hole of 3 -in. diam opening from the large chamber. The other was black with a 3-in. square opening. The floors of both small chambers were $1 / 8$-in. stainless steel grids, $1 / 2$ in. on center and connected to a Grason-Stadler shock scrambler set to deliver 5-mA shock. A 100-W flood lamp was suspended $12 \mathrm{in.} \mathrm{above} \mathrm{the}$ c $\in$ nter of the large chamber.

The ECS in this experiment was delivered by an apparatus which generated $42 \mathrm{~mA}$ at $1,200 \mathrm{~V}$ ac for $0.5 \mathrm{sec}$.

\section{PROCEDURE}

Suboski et al's (1969b) pretraining procedure, consisting of four alternated free- and forced-choice trials, was used in the experiment. On each of the pretraining trials, given one per day, each of the 120 Ss was placed behind a Plexiglas panel held across the right angle of the large chamber. The panel was removed after $10 \mathrm{sec}$, and $2 \mathrm{~min}$ after $\mathrm{S}$ entered one of the small open chambers, it was returned to its home cage. Alternated free and forced trials were given with the door to the previously chosen chamber blocked on forced trials. Both chambers were accessible for entry on free trials.

Fifteen rats were allocated to each of eight different groups after pretraining. On the fifth (free-choice) day, four groups received a $5 \cdot \mathrm{mA}$ shock upon entering a small chamber. The remaining four groups were not shocked. Of the entrance shock Ss, two groups (shock-ECS 100) were convulsed by a $0.5 \cdot \mathrm{sec} 42 \cdot \mathrm{mA}$ ECS $100 \mathrm{sec}$ after footshock. The two other entrance shock groups (shock control) received a pseudo-ECS at an identical interval. Of the Ss not previously treated with footshock, two groups (ECS control) were convulsed $100 \mathrm{sec}$ after entering the small chamber, the remaining two (normal control) receiving a pseudo-ECS at an identical interval. Thus, two groups received each of the four experimental treatments. Of these two groups, one received a free-choice test trial $24 \mathrm{~h}$ after treatment, the other received two free-choice test trials 30 and 31 days after treatment. During test trials, Ss were placed behind a Plexiglas barrier across the right angle of the large chamber. The panel was removed after $30 \mathrm{sec}$, and latency to enter a small chamber and whether the chamber chosen was opposite the one entered during the treatment trial (reversals) was noted.

\section{RESULTS}

Figure 1 shows the mean latency of small-chamber entry, mean number of boluses eliminated, and number of reversals for all groups during tests performed 1,30 , and 31 days after treatment. The typical reduction in latency of small-chamber entry as a 

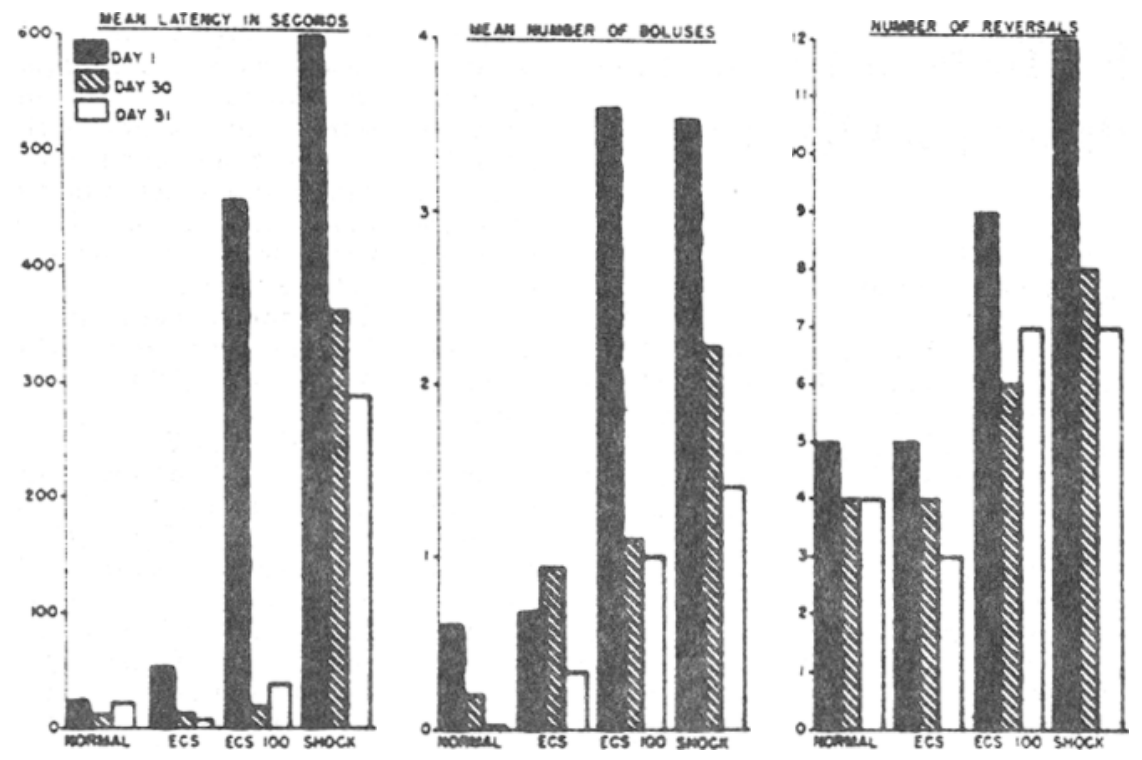

Fig. 1. Mean latency in seconds, mean number of boluses, and number of reversals by the normal control, shock control, ECS control, and shock-ECS 100 groups on the 1st, $30 \mathrm{th}$, and 31 st days after treatments. These groups are designated in the figure as normal, shock, ECS, and ECS 100, respectively.

consequence of convulsion appeared on all three tests. The differences in latency between the shock-control and shock-ECS Ss persisted long after treatment, in spite of an overall reduction in latency for all groups. Because tests on Days 30 and 31 were confounded with time after treatment, an analysis of variance was performed on the natural logarithm transforms of individual scores of only the tests conducted 1 and 30 days after treatment. This analysis indicated that both the latency differences between groups and the overall reduction in latency between Day 1 and Day 30 tests was significant $(\mathrm{F}=28.65, \mathrm{df}=$ $3 / 112, \mathrm{p}<.01$, and $\mathrm{F}=20.64$, df $=$ $1 / 112, \mathrm{p}<.01$, respectively). Moreover, the variance due to the interaction between groups and tests also proved to be significant ( $F=5.47$, $\mathrm{df}=3 / 112, \mathrm{p}<.01$ ), a result which emphasized that the latency differences between groups becomes accentuated rather than decreased with time following treatment. Rather surprising was the outcome of an orthogonal comparison which indicated that the latency difference between the shock-ECS 100 and shock-control groups did not nearly achieve significance $(F=.24, \mathrm{df}=$ $1 / 112$ ) on the day after treatments, although this difference was significant $(F=14.36, \mathrm{df}=1 / 112, \mathrm{p}<.01) 30$ days after treatment. However, on both tests, shock-control and shock-ECS 100 Ss took a significantly $(F=78.5, \mathrm{df}=1 / 112, \mathrm{p}<.01$, and $\mathrm{F}$ $=14.98, \mathrm{df}=1 / 112, \mathrm{p}<.01$, respectively) longer time to enter the small chamber than did normal and ECS control Ss.

The number of boluses appears to be greater for animals which received footshock than for animals which did not. Moreover, no substantial differences in mean number of boluses were apparent between the shock-control and the shock-ECS 100 groups. Although Fig. 1 indicates that these differences were maintained regardless of when the test followed the treatment, an overall reduction in boluses occurred on later test sessions. An analysis of variance performed on the defecation data of only the Day 1 and Day 30 test sessions revealed that the differences in mean number of boluses between groups were significant $(F=10.15, \mathrm{df}=3 / 112$, $\mathrm{p}<.01)$. In addition, mean number of boluses eliminated was reduced significantly on the Day 30 test below the Day 1 test $(F=6.83, \mathrm{df}=1 / 112$, $p<.01$ ); however, the variance due to the interaction of groups with test time was not $(F=2.58, \mathrm{df}=1 / 112)$. Orthogonal comparisons indicated that on both Test Days 1 and 30, defecation by the normal and ECS control Ss was significantly less than the shock-control and shock-ECS 100 Ss $(F=30.40, \mathrm{df}=1 / 112, \mathrm{p}<.05)$; however, differences between the two groups which received footshock, regardless of test day, was not $(F=$ $.01, \mathrm{df}=1 / 112$, and $\mathrm{F}=2.54, \mathrm{df}=$ 1/112).

Figure 1 shows that the normal and ECS control groups tended to perseverate in their choice of the small chamber on tests run $24 \mathrm{~h}$ after treatment, whereas Ss of the shock control group in a majority of cases entered the chamber in which they had not received footshock. The shock-ECS group occupied an intermediate position between these two extreme groups. Across successive tests on the 30 th and 31 st day after treatment, an overall reduction in reversals appeared for all groups, and the difference between the shock-control and shock-ECS Ss was reduced on these test sessions. The analyses support these observations, since the differences in the number of reversals between groups were significant $\left(x^{2}=9.28, \mathrm{df}=3, \mathrm{p}<.05\right)$ on tests run $24 \mathrm{~h}$ but not $\left(\mathrm{x}^{2}=3.16\right.$, $\mathrm{df}=3, \quad \mathrm{p}<.20) \quad 30$ days after treatment. An additional chi-square test revealed that on the test session 1 day after treatment, the normal and ECS control Ss did not reverse less often than the shock-ECS 100 Ss $\left(\mathrm{x}^{2}=\right.$ 92, $\mathrm{df}=1$ ). A Fisher's exact test indicated that shock-ECS 100 and shock-control Ss also did not significantly differ in reversal behavior. Since there were significant differences in number of reversals between groups on the test session $24 \mathrm{~h}$ after treatment, the conclusion must be drawn that normal and ECS control Ss show a significantly different number of reversals than the shock-ECS 100 and shock-control groups.

\section{DISCUSSION}

The ECS-produced reduction in latency for entering the small chamber apparent on the test day $24 \mathrm{~h}$ after treatment was maintained, and even increased, the further in time that the test trial followed the treatement trial. Therefore, this experiment using a one-trial discriminated avoidance paradigm represents firm evidence that the effect of ECS on latency is maintained up to a month after treatment. This result agrees with the outcomes of several studies using passive avoidance procedures (e.g., Greenough, Schwitzgebel, \& Fulcher, 1968, King \& Glasser, 1970), but is not consistent with the results of other passive avoidance experiments (e.g., Pagano, Bush, Martin, \& Hurt, 1969; Riddell, 1969). As previously stressed (Spevack \& Suboski, 1967, 1969), however, a valid test of the effect of ECS on memory can best be made by an examination of discrimination performance. This study was designed to test the hypothesis that the effect of ECS on discrimination performance demonstrated in previous studies (Suboski et al, 1969b) could be attributed to transitory effects on performance rather than to interference with memory. Although the data from the 24-h posttreatment test, as in Suboski et al's (1969b) study, showed an apparent 
ECS-produced discrimination deficit, whether or not such a deficit is removed by time still remains an unanswered question. The ECS-produced discrimination deficit on the Day 1 test was slight and not significant. The Day 30 deficit was even smaller, possibly because of the poorer discrimination shown by nonconvulsed Ss 30 days after treatment. It is, however, interesting to observe that the shock-ECS $100 \mathrm{Ss}$ on the 30-day test still showed discrimination consistently superior to that of either the normal or the ECS control Ss.

In this study, the data showed that, even though convulsions decrease the latency of small-chamber entry on the test trial, ECS does not have a concomitant effect on defecation. Number of boluses eliminated by shock-ECS and shock-control Ss were not found to be significantly different, even though latencies for entering the small chamber on test days were. This results serves to emphasize that ECS alters latencies, not indirectly by reducing emotionality, but directly by modifying motor behavior, as has been suggested by Chorover \& Schiller (1966).

\section{REFERENCES}

BRENGELMANN, J. C. The effects of repeated electroshock on learning in depressives. Berlin: Springer-Verlag, 1959.

CHOROVER, S, L, \& SCHILLER, $P, H$. Reexamination of prolonged retrograde amnesia in one-trial learning. Journal of Comparative \& Physiological Psychology, $1966,61,34-42$.

GREENOUGH, W. T., SCHWITZGEBEL, $R$. L., \& FULCHER, J. K. Permanence of ECS-produced amnesia as a function of test conditions. Journal of Comparative \& Physiological Psychology, 1968, 66, 554-556.

KING. R. A., \& GLASSER, R. L. Duration of electroconvulsive shock-induced retrograde amnesia in rats. Physiology \& Behavior, 1970, 5, 335-339.

PAGANO, R. R., BUSH, D. F., MARTIN,
G.. \& HUNT, E. B. Duration of retrograde amnesia as a function of electroconvulsive shock intensity. Physiology \& Behavior, 1969, 4, 19-21.

RIDDELL, W. I. Effect of electroconvulsive shock: Permanent or temporary retrograde amnesia. Journal of Comparative \& Physiological Psychology, $1969,67,140-144$.

SPEVACK, A. A., RABEDEAU, R. G., \& SPEVACK, M. E. A temporally graded ECS function following one-trial learning. Psychonomic Science, 1967, 9, 153-154.

SPEVACK, A. A., \& SUBOSKI, M. D. A confounding of conditioned suppression in passive avoidance: ECS effects. Psychonomic Science, 1967, 9, 23-24.

SPEVACK A A. \& SUBOSKI, $M$. Retrograde effects of electroconvulsive shock on learned responses. Psychological Bulletin, 1969, 72, 66-76.

SUBOSKI, M. D., BLACK, M., LITNER, J., GRENNER, $R$, $T$ \& SPEVACK A. A. Long and short-term effects of ECS following one-trial discriminated avoidance conditioning. Neuropsychologia, $1969 \mathrm{a}, 7,349-356$.

SUBOSKI, M. D., SPEVACK, A. A., LITNER, J., \& BEAUMASTER, E. Effects of ECS following one-trial discriminated avoidance conditioning. Neuropsychologia, 1969b, 7, 67-78. 